\title{
The media paradox: influence on human shark perceptions and potential conservation impacts
}

\author{
Raquel Lubambo Ostrovski ${ }^{1,2 *}{ }^{\mathbb{D}}$; Guilherme Martins Violante $^{1}$; \\ Mariana Reis de Brito ${ }^{(\mathbb{D})}$; Jean Louis Valentin ${ }^{(\mathbb{D}}$ and Marcelo Vianna ${ }^{2,3}$
}

\begin{abstract}
Sharks, due to some of their characteristics such as prominent teeth and size, cause fear in many people. This feeling can be evidenced due to encounters with these animals or sustained by media information. Currently, negative information on these animals, present in movies and the news, for example, has contributed to a worldwide feeling of "fear" or "anger" towards sharks in the general public. On the other hand, efforts to better understand these animals have increased. In addition to films and documentaries, many scientific and environmental education groups have attempted to improve or alleviate, public perception concerning this significant fear and promote shark conservation. In this context, we analyzed the perceptions of 354 people living in Rio de Janeiro, a coastal city in southeastern Brazil, by applying a structured online questionnaire about sharks. The findings reported herein indicate direct media influence on respondent perceptions, according to the "good" or "bad" image that media vehicles pass on concerning these animals, and that, despite an established fear of sharks, public support for their conservation is maintained. The factor analysis indicated a relationship between older people and more fear, and less fear among people aged 20-40 years. We believe that the lesser fear in the latter is related to the influence of the current media in this age group, such as documentaries and social networks, while older respondents lived in a period with less environmental information and became more susceptible to shark negative films and media, in which the fear persists today.
\end{abstract}

Keywords: Shark Framing; Human-Shark Interactions; Environmental Perception; Media Influence; Conservation.

1 Pontifícia Universidade Católica do Rio de Janeiro (PUC-Rio), Departamento de Biologia, CCBS-Centro de Ciências Biológicas e da Saúde, 22451-900 Rio de Janeiro, RJ, Brazil.

2 Universidade Federal do Rio de Janeiro (UFRJ), Departamento de Biologia Marinha, CCS-Centro de Ciências da Saúde, Bloco A, sala 054, 21949-900 Rio de Janeiro, RJ, Brazil.

3 Rio de Janeiro Aquarium Research Center (IMAM - AquaRio), Rio de Janeiro, Brazil.

* Corresponding author $\bowtie$. E-mail address: RLO (raquelubambo@gmail.com), GMV (gm.violante0@gmail.com), MRB (marianareis2002@hotmail.com),.JLV (jeanlv@globo.com), MV (mvianna@biologia.ufrj.br) 


\section{SIGNIFICANCE STATEMENT}

Nowadays, the media is responsible for shaping people's opinion due to several information available. Considering this, we evaluated people's perceptions of sharks and their fear. With that, we interviewed 354 residents of Rio de Janeiro to evaluate their feelings about sharks and their conservation. Based on their answers, most of them have already been in contact with sharks, through documentaries, movies, news, aquariums and nature, and a high proportion of the interviewed had a huge fear of those animals. In spite of the fear, $94 \%$ of those people were in favor of shark conservation, recognizing their importance for marine ecosystems. Understanding people's perception of sharks in the modern world, and the media role shaping this perception, may reveal into a big help to achieve shark conservation, seen that with the population support, conservation of any species has more chances of success, as shown by some modern published work.

\section{INTRODUCTION}

Media vehicles are the most expressive forms of information, representation, identity and expression through which people obtain information and values. These vehicles present information on the current society and worldwide events to the general population. However, they do not, in many cases, reflect reality and cannot be considered an absolute truth, and a greater than informative economic character attributed to these means of information is noted (Andrelo and Almeida 2015). Published news pieces are influenced by the way they are reported, according to the interests of those who inform them and the feelings they wish to arouse in the viewers or readers. This is noted for all media vehicles, like newspapers, films, cartoons and advertisements, among others, and is due to persuasion, opinion formation, culture shock, alienation, rejection or simply information presentation, and, may or may not be carried out according to plan. This applies to both social issues, such as "marketing", and environmental issues (Alexandre and Fernandes 2006). As nature does not "speak for itself", communication is the the main way to obtain environment and environmental issue information. In this context, the media acts as the main societal means to obtain information on nature, which is, in turn, considered as a public and political interest, especially regarding environmental problems, although these vehicles can cover much more, such as the way we perceive and value the environment (Hansen 2010). Some authors consider that even documentaries, which aim to be "nature biographies", usually present dramatizations, acquiring a "Hollywood" character of pure representation applied to a story narrative (Bousé 1998). In addition, the entertainment media seeks impactful audience reactions, and frequently applies certain techniques, like "closeups" to provide a feeling of intimidation by certain animals (Bousé 2003) when filming natural or purposeful animal behaviors, often stimulated by the filmmakers themselves (Bousé 1998). Many behaviors recorded in front of the cameras are induced by the presence of humans in the natural habitat (Bousé 1998), and are registered and disseminated among the population, which can generate diverse public reactions. In this regard, media vehicles idealize, build and disseminate the natural environment views that best suit them, which may generate either positive and negative perceptions, as two extreme views of nature, which are articulated and shaped over time, may be presented (Hansen 2010). Until very recently, shark information was usually based on popular myths and experiences. Sailors from ancient times, fearing sea creatures from new oceans, treated sharks as terrible and monstrous animals, a view still frequently observed in many people today (Francis 2012). In addition, their large size (some can reach up to $18 \mathrm{~m}$ ), fusiform body, and at least two rows of teeth, aid in their representation as monsters (Liberal et al. 2006). The release of Peter Benchley's 1974 "Jaws" book, and especially the 1975 Steven Spielberg film, was the forerunner of negative view bestowed upon these animals. As sharks became more fearsome, the media increasingly exploited them in a negative sense, to gain an audience for a subject that mobilized most of that period's population (Francis 2012). On the other hand, one study carried out with people who lived in contact with these animals reported no fear of sharks by this population, who, indeed, highly valued their ecological importance (Francis 2012). Unfortunately, only a small percentage of humans have had the opportunity to interact with sharks, and most are only bombarded with information that does not necessarily express the reality of these animals, but only commercially interesting aspects (Friedrich et al. 2014). Shiffman et al. (2020) demonstrated that people have a limited sense of the current threats that sharks suffer. In general, they do not know which species are most threatened and are unaware of the appropriate solutions to solve the problems associated to this taxonomic group. The authors affirm that this lack of knowledge is due to erroneously propagated information and a lack of adequate communication from the scientific community.

In this scenario, sharks became known as "killer machines", leading to worldwide impacts on their conservation (Francis 2012). Many American fishers, after watching "Jaws", immediately took their boats 
out to fish these fearsome "death machines", guided by feelings caused by the film. However, in Australia, the population that routinely co-existed with many shark species was not even aware that they could attack humans (Francis 2012). In 2005, George Burgess, from the University of Florida, stated that elasmobranch populations have declined considerably due to fishing, with many species reaching up to $90 \%$ declines from their original populations (Francis 2012), and that $16 \%$ of all species are endangered, according to the IUCN Red List (Dulvy et al. 2014).

On the other hand, scientists and naturalists have become increasingly concerned with the shark conservation status, and several conservation organizations have mobilized worldwide with a discourse aimed at preserving these animals, differing from other forms of popular communication (Francis 2012). The impacts that humans have on the oceans and their consequences to our own survival become increasingly evident each day. Actions are required not only by governments, but by society (Friedrich et al. 2014). In this context, one wonders how it would be possible to convince people to conserve animals seen in their imagination as "deadly machines", as this pervasive negative image may restrict popular participation in defending shark conservation (Friedrich et al. 2014). There are some solutions that help improve shark image nowadays, promoting their conservation and causing proximity between sharks and humans; and aquariums are one of them. Since past decades, animals have been used in entertainment in order to amaze and entertain people (Alves and Barboza 2018); however, with all present extinctions of wildlife, institutions like aquariums and zoos have become great places for preserving wildlife, by conservation in situ, promoting a connection between wild animals and people and, by environmental education, inform the public more about the animal's ecology and importance in the wild (Gusset and Dick 2010, Buckley et al. 2020).

Currently, several media are available for public entertainment, and all present a specific bias according to the interests of their producers (Bousé 1998), however, the shark-focused media has presented a dual shark perception over time. For example, besides "Jaws" (Steven Spielberg 1975), other films such as "Open Water" (Chris Kentis 2003), "The Shallows" (Jaume Collet-Serra 2016), "47 meters down" (Johannes Roberts 2017) and "The Meg "(Jon Turteltaub 2018) all present negative shark aspects. Animations, on the other hand, like "Jabberjaw" (Joe Ruby and Ken Spears, 1976), "Finding Nemo" (Andrew Stanton 2003), "Shark Tale" (Rob Letterman, Bibo Bergeron and Vicky Jenson 2004), "Zig \& Sharko" (Olivier Jean-Marie 2010), "Shark" (Paul McGann 2015) and "Baby Shark" (Pinkfong
2016) contemplate the positive side of these animals.

Some studies have demonstrated a significant media influence on people's perceptions and views on nature (Andrelo and Almeida 2015; Bousé 1998), and some have even reported more specific data (Francis 2012; Friedrich et al. 2014; Neff 2014), for example, analyzing the influence of the film "Jaws" on public perceptions and its consequences on shark conservation. Other assessments (Lucrezi et al. 2018; O'Bryhim and Parsons 2015) have discussed more general popular shark perceptions and possible impacts on their conservation. However, a knowledge gap regarding the influence of media vehicles other than films, such as documentaries and news pieces, among others, is noted concerning general public shark perceptions and their impacts on conservation.

Nowadays, it is important for scientists to rely on both conventional - papers, technical reports, visual census - and non-conventional methods of gathering scientific information (Saldaña-Ruiz et al. 2017); these non-conventional sources can be represented by local ecological knowledge, that is mainly studied by Ethnobiology. Two derivatives of ethnobiology used on the present work are ethnozoology and ethnoichthyology, in which both of them integrates elements of social and natural sciences (Alves and Souto 2015). Besides that, ethnozoology and ethnoichthyology can help by improving and understanding the symbolic study of fauna (France 2019), also contributing for meaningful conservation actions with help from the general public (Barbosa-Filho et al. 2020), as can be seen in some present studies (Marques et al. 2019).

Sharks are slow growing animals, displaying late sexual maturation, low fertility and long gestation periods (Cortés 2000). This set of biological characteristics results in slow population increases, making them more susceptible to the high mortality rates caused by fishing (Cortés 2002; Dulvy and Forrest 2010; García et al. 2008; Musick 1999). Thus, understanding potential causes that may contribute towards their decline, both directly and indirectly, is paramount. In this context, the aim of this study was to identify public shark perceptions, analyzing the paradox resulting from different forms of entertainment and the possible impact of these perceptions on shark conservation.

\section{MATERIAL AND METHODS}

This study was carried out focusing on the population living in the city of Rio de Janeiro, a coastal city in southeastern Brazil. A structured questionnaire based on models applied by other authors (Liberal et al. 2006; Lucrezi et al. 2018; O'Bryhim and Parsons 2015) was used for data collection, in order to obtain information about possible media influences on public shark perceptions and to verify whether this percep- 
tion can lead to impacts concerning the conservation of these animals. The questionnaire was sent via the Internet, through the "Google Forms" application system, and then released on the WhatsApp, Facebook and Instagram social networks. People belonging to any age group and school level were invited to participate, and all respondents answered the questions voluntarily. This study was approved by the Pontifical Catholic University of Rio de Janeiro Research Ethics Council (CEPq/PUC-Rio) 116/2019, under protocol no. $130 / 2019$.

The questionnaire was available for online completion from 25 to 30 May 2019. Questions comprised information on age, gender, schooling level, field of activity, source of shark information, media seen by the interviewees, amount of fear (on a scale from 0 to 10, with 10 representing the highest amount of fear), the justification of said fear, records of shark proximity, science and opinion about shark slaughter and shark threats and conservation. Most questions had set answer boxes, although a text box for free writing was available for more elaborate questions.

Data were treated as percentages and graphs were plotted for better data visualization (Brower and Zar 1984). The "Word Cloud" methodology was used to analyze the responses (Berteaux et al. 2017). This program allows for visual result presentation, distinguishing more and less frequently used text words, generating a "cloud", which can be shaped as a silhouette of the researcher's choice. The free software "WordClouds.com" (https://www.wordclouds.com) was used to generate the images, in order to represent the most frequent quotes from two groups based on the applied fear scale: one with fear values ranging from 0 to 5 , considered as "low fear" responses, and another with fear values ranging from 6 to 10, considered as "high fear" responses.

After a descriptive analysis of the questionnaire responses, we performed a relational approach between the variables, aiming to answer questions such as which people, age, sex, education, are or not afraid of sharks, declare themselves knowledgeable about the subject and are or not in favor of their protection. Due to the qualitative nature of the responses, the Correspondence factor analysis (CA) method was applied (Legendre and Legendre 1998). Correspondence factor analysis is a multivariate technique that may be applied to any type of data and to any number of data points. It is a technique with which is possible to find a multidimensional representation of the dependencies between rows and columns in a low dimensional space. It allows the construction of an orthogonal system of axes (called factors) where observations (rows of the table) and variables (columns of the table) can be simultaneously displayed. In this system proximity between observations or between variables is interpreted as strong similarity. The usual output from a correspondence analysis includes the "best" two-dimensional graphical representation of the data, the co-ordinates of the plotted points and a measure of the amount of information retained in each dimension. Before applying the CA, a binary transformation of the response variables was necessary. A categorization of the variables was previously performed, assigning 1 or 0 to each response category (Table 1$)$. The analysis was performed using the Statistica Program v, 7.1 (STATSOFT 2005).

\section{RESULTS}

A total of 354 questionnaires were answered. Gender, age, schooling, training and professional data are described in Table 2.

Concerning source of information on sharks, the most accessed by the respondents were stated as documentaries (27.4\%), websites/social networks (19.0\%), news pieces (17.9\%) and films/animations (17.1\%). The most seen were "Finding Nemo" (19.4\%), "Shark Tale" (15.4\%), "Jaws" (14.4\%) and "Jabberjaw" (12.1\%) (Figure 1).

Answers regarding fear were varied, but highly concentrated on the 10 scale $(32.8 \%)$, followed by 8 $(13.6 \%)$ and $5(13.3 \%)$. Fear on the zero-scale was noted for only $2.8 \%$ of the respondents and a fear value of 1 was the least selected (1.1\%) (Figure 2). The next question, which asked for a justification for the chosen fear scale value, presented mostly negative responses $(63.6 \%)$, followed by positive (18.6\%) and neutral $(17.8 \%)$ answers.

In the case of having a close encounter with a shark, $63.0 \%$ people wither saw or were in the presence of one, while $37.0 \%$ had never had any contact. Of this percentage, a total of $66.8 \%$ were in the presence of this animal in an aquarium, $16.6 \%$ had this contact in the wild and $16.1 \%$ had contact with sharks both in aquaria and in the wild. A total of $80.5 \%$ of respondents would like to see sharks for the first time or again and $19.5 \%$ would not like to see sharks or see them again. Among people who had seen a shark, $14.8 \%$ would not like to see this animal again (Yes_No), while $85.2 \%$ would like to see it again (Yes_Yes). On the other hand, among people who had never seen a shark, $72.5 \%$ would like to see one for first time (No_Yes) and $27.5 \%$ would not (No_No) (Figure 3).

Concerning responses about adopting the death of sharks as an alternative to reduce attacks on humans, most responded negatively to this practice, with sadness $(54.5 \%)$ and anger $(28.8 \%)$ as the most frequently selected options. Most respondents are aware that sharks are threatened, and fishing (27.5\%) and hu- 
Table 1. Variables/answers categorization to the Correspondence factor analysis. The codes used in the factorial analysis are informed on the table below, representing the interviewed main views.

\begin{tabular}{|c|c|}
\hline Variables/Answers & Codes \\
\hline \multicolumn{2}{|l|}{ Age } \\
\hline Less than 20 years & $<20 y$ \\
\hline From 20 to 40 years & $20-40 y$ \\
\hline More than 40 years & $>40 y$ \\
\hline \multicolumn{2}{|l|}{ Gender } \\
\hline Female & $\mathrm{F}$ \\
\hline Male & M \\
\hline \multicolumn{2}{|l|}{ Schooling } \\
\hline Middle school & MSch \\
\hline High school & HSch \\
\hline Superior & SSch \\
\hline Post-graduation & Pgrad \\
\hline \multicolumn{2}{|l|}{ Source of information } \\
\hline Movies-Animation & Mov \\
\hline Documentaries-Journal-Papers & Doc \\
\hline Social Media-People-News & Med \\
\hline \multicolumn{2}{|l|}{ Fear level } \\
\hline No or small fear & $0-3 \mathrm{~F}$ \\
\hline Middle fear & $4-7 \mathrm{~F}$ \\
\hline High fear & $8-10 \mathrm{~F}$ \\
\hline \multicolumn{2}{|l|}{ Shark proximity } \\
\hline Yes & YSee \\
\hline No & NSee \\
\hline \multicolumn{2}{|l|}{ Encounter site } \\
\hline Nature & Natu \\
\hline Aquarium & Aqua \\
\hline Both & Both \\
\hline \multicolumn{2}{|c|}{ Would you like to see it? If already, would you like to see it again? } \\
\hline Yes & Ylike \\
\hline No & Nlike \\
\hline \multicolumn{2}{|l|}{ Feelings about shark killing / overfishing } \\
\hline Sad-Angry-Surprised-Shocked & Sad \\
\hline Indifferent-Relieved-Inefficient & Indif \\
\hline \multicolumn{2}{|l|}{ Are there any threats to sharks? } \\
\hline Yes & Ythreat \\
\hline No or a few & Nthreat \\
\hline \multicolumn{2}{|l|}{ Possible threats } \\
\hline Fishing & Hunt \\
\hline Pollution & Pollu \\
\hline Climate & Clima \\
\hline Other threat & OthThr \\
\hline \multicolumn{2}{|l|}{ Protection } \\
\hline Yes & ProtY \\
\hline No, Maybe, Don't know know & ProtN \\
\hline
\end{tabular}

mans $(26.5 \%)$ were the most cited factors. Only $6.0 \%$ of the respondents demonstrated a lack of knowledge concerning the fact that sharks undergo several types of threat, and fortunately, only $3.6 \%$ of the respondents indicates that these animals are not threatened. Most responses were positive regarding the need to protect sharks $(94.4 \%)$, and only $2.8 \%$ were against this (Figure 4).

Part of the interviewees said they were afraid of sharks due to media influences, with 51 citing the media, with media type not specified in $52.9 \%$ of these cases, while $29.4 \%$ cited films, $5.9 \%$ news, $7.8 \%$ doc- 
Table 2. Demographic profile of the study participants, Rio de Janeiro, Brazil, residents in May 2019.

\begin{tabular}{ll}
\hline \hline \multicolumn{1}{c}{ Variables } & \multicolumn{1}{c}{ Percentages } \\
\hline \hline Gender (\% female and male) & $66.7 \%$ female and 33.3\% male \\
Age (mean \pm SD, min-max) & $31.9 \pm 16.1,6-77$ \\
Schooling level (\%) & $3.3 \%$ incomplete higher education, 21.8\% postgraduation, 16.7\% \\
& complete higher education, 14.1\% complete high school, 7.0\% in- \\
& complete high school and elementary school \\
Main university courses (\%) & 25\% Biology, 7.4\% Law, 5.2\% Linguistics, Medicine and Psychol- \\
& ogy, 62.5\% others \\
Main professions (\%) & $9.9 \%$ teacher, 5.2\% biologist, 4.7\% doctor \\
\hline \hline
\end{tabular}

A

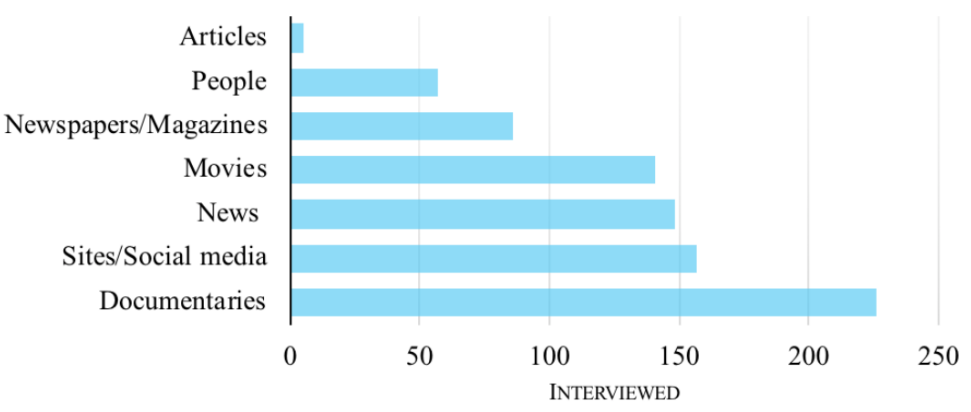

B

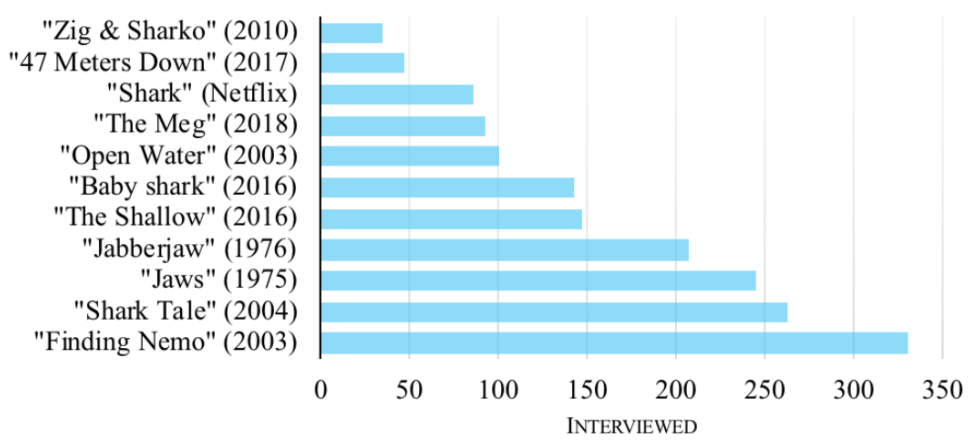

Figure 1. A) Information sources cited by the respondents, with documentaries ranking first, with 226 responses. (B) Media viewed by the respondents, with "Finding Nemo" ranking first, cited 331 times. Interviews were conducted with Rio de Janeiro, Brazil, residents in May 2019.

umentaries and $3.9 \%$, websites/social networks. In addition, seven people displayed little fear (between $0-5)$, one of whom showed a positive response concerning documentaries, while the other six displayed negative responses, but said they were not influenced by the media. A total of 43 people cited the media and were most afraid (between 6-10), with one respondent showing a positive response to documentaries and all others answering with negative quotes. Some of the given answers are presented below:

- "Because I watch documentaries and understand, why they do it" (positive answer).

- "Despite knowing how much they are shown as terrorists in the media, I find everything very dramatic."

- "Related news is always about tragedies."

- "Because of movies where sharks eat people."

- "The media does not give us a good view on animals."

- "They seem aggressive and news/social networks help increase fear by always commenting on bad facts with sad consequences."

- "In general, the media places sharks as beings about to devour humans, even though sharks 


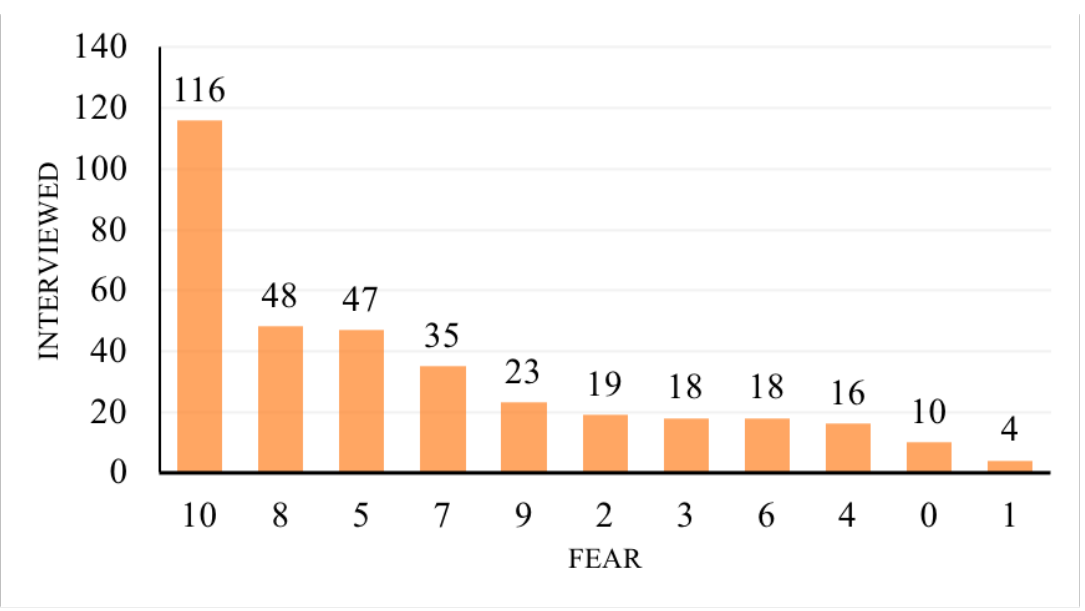

Figure 2. Shark fear ranking of the study respondents that live in Rio de Janeiro, Brazil, where a fear value of 10 is the highest and most present.

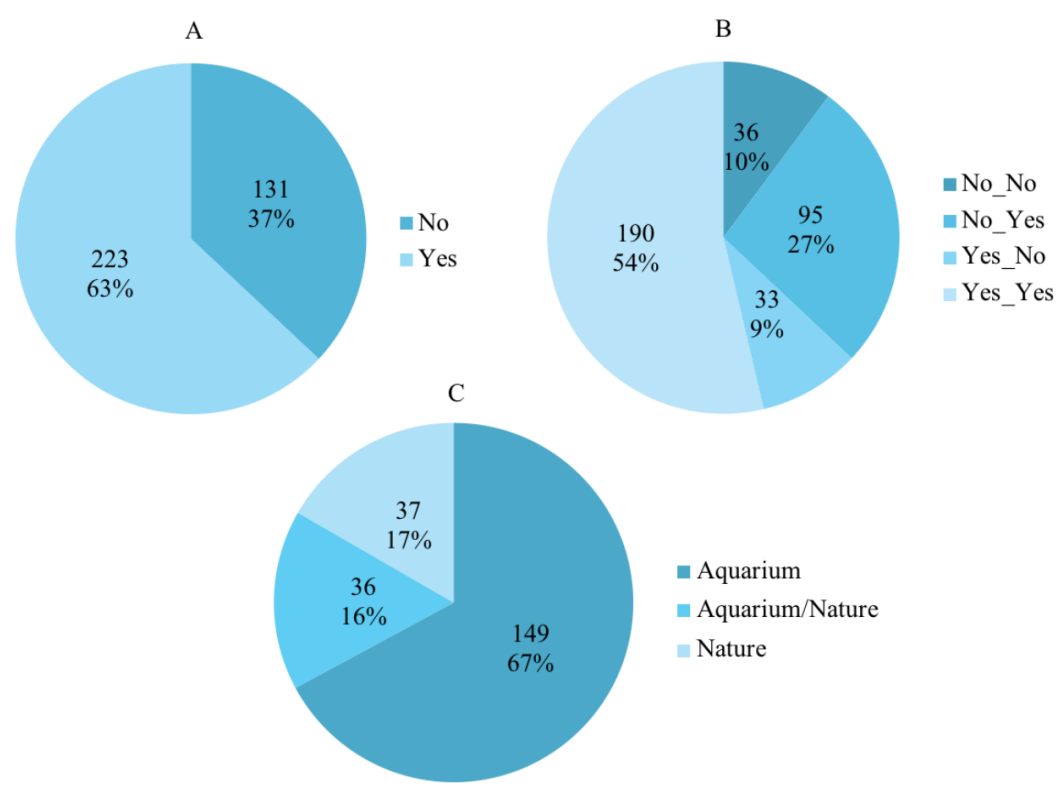

Figure 3. (A) Number of respondents who did or did not encounter sharks at some point in their lives. (B) Number of respondents who had been in the presence of a shark and would like to (Yes_Yes) or not (Yes_No) again, and if they had not yet had this experience, would like to (No_Yes) or not (No_No). (C) Location of respondents who had seen a shark and where this experience happened (aquaria and/or wild).

present different behaviors, and there is always a significant amount of fear."

- "The media gives me a biased view that sharks would swallow me just by me being around them."

- "They are dangerous animals, but I know that movies exaggerate reality a lot."

- "Mostly because of the psychological fear that films/media created about sharks. But, at the same time, they are carnivorous animals and there are many cases of attacks."

- "Most of the times, when we do obtain information on sharks, it is directly related to the violence they cause, either through attacks or by reports in films and documentaries."

The Word Cloud displayed in Figure 5 was plotted with the responses of the 114 people who scored less fear (from 0-5), where sentences with similar meanings were grouped in keywords to facilitate visualiza- 


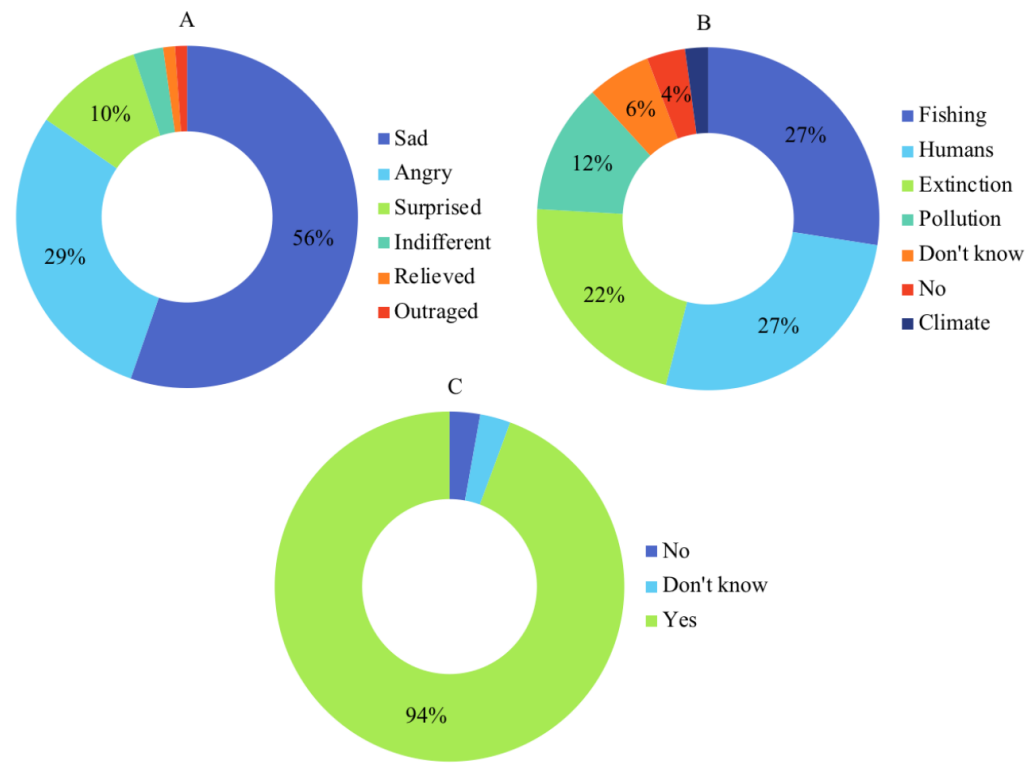

Figure 4. (A) Respondent responses concerning shark hunting adoption policies as a measure to reduce attacks on humans. (B) Respondent responses regarding threats towards sharks. (C) Respondent responses regarding the need to protect sharks.

tion. The most frequent words were "Rare attacks", "No contact", "Fear' and "Respect" (Figure 5). The Word Cloud displayed in Figure 6 was plotted with the responses of the 240 people who were most afraid (of 6-10). The most frequent words were "Fear", "Dangerous", "Attacks", "Predator" and "Movies" (Figure 6).

The analysis of the factor plan I-II of the CA and the proximity between the points (Figure 7) reveal relationships between the questionnaire responses. We verified the importance of the Age factor, which contributes to most of the inertia in the first axis. Most of the younger respondents $(<20 \mathrm{y})$ have basic or secondary education and confess to not ever having seen sharks (Negative coordinates on axis I of the variables "MSch", "<20y", "HSch" and "NSee"). On the other hand, the variables "> 40y", "Pgrad", "ProtN", "Indif" and "Nthreat" were located on the positive side of factor I. Most comprise people over 40, with postgraduate degrees, who consider that sharks are not threatened, do not need protection and are indifferent or relieved with the fact that these animals are hunted. The responses of respondents between 20 and 40 are more diversified and contribute to the inertia of axis II. Most do not or have little fear ("0-3F", "4-7F") and social media, documentaries and articles are their main sources of information. They consider that the main threats are pollution and, mainly, climate change (strong negative "Climate" coordinate in axis II), without excluding, however, hunting.

A difference between women $(\mathrm{F})$ and men $(\mathrm{M})$ is noted in axis II. Both consider that sharks are threatened and must be protected, but women are more afraid ("8-10F"), although they are more sad, shocked and angry about shark killing. In the same axis, located on strongly positive coordinates, some younger women $(<20 y)$ with elementary and middle education level have never seen sharks and would not like to see them, but, even so, are very afraid.

\section{DISCUSSION}

The use of social networks to access respondents may have resulted in study limitations. As the questionnaire was disseminated through the authors' personal contacts, the data can be traced to a specific part of the population. However, despite the possible homogeneity of the interviewed public, given by the contingent of responses from graduate biology students or trained biologists, this research is still relevant, as this population did not represent most respondents. Regardless, the results reported herein contribute towards a better understanding of shark perceptions for the population of Rio de Janeiro, since the sample group was quite diverse, composed of representatives of various ages, occupations and social classes. Rio de Janeiro is a coastal city with a strong vocation for tourism, water sports, fishing and other marine themes. These limitations have already been described by other studies (Friedrich et al. 2014) and, according to the authors, even though the respon- 


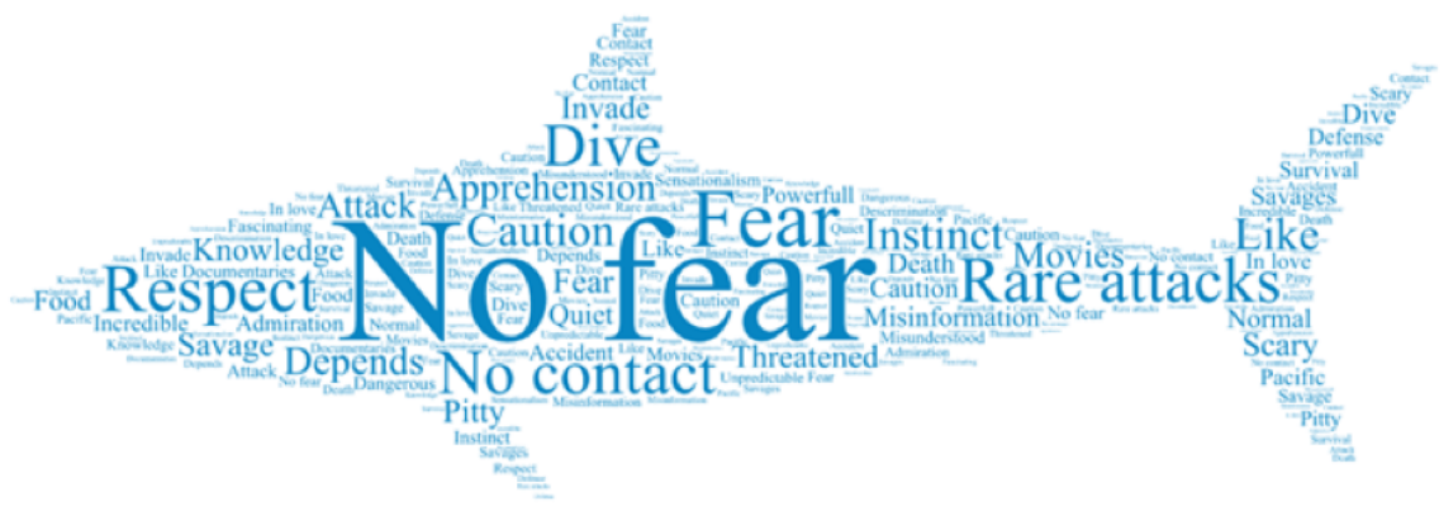

Figure 5. Word Cloud concerning the lowest shark scale fear range, between 0-5 $(n=114)$ of respondents residing in Rio de Janeiro, Brazil, in May 2019.

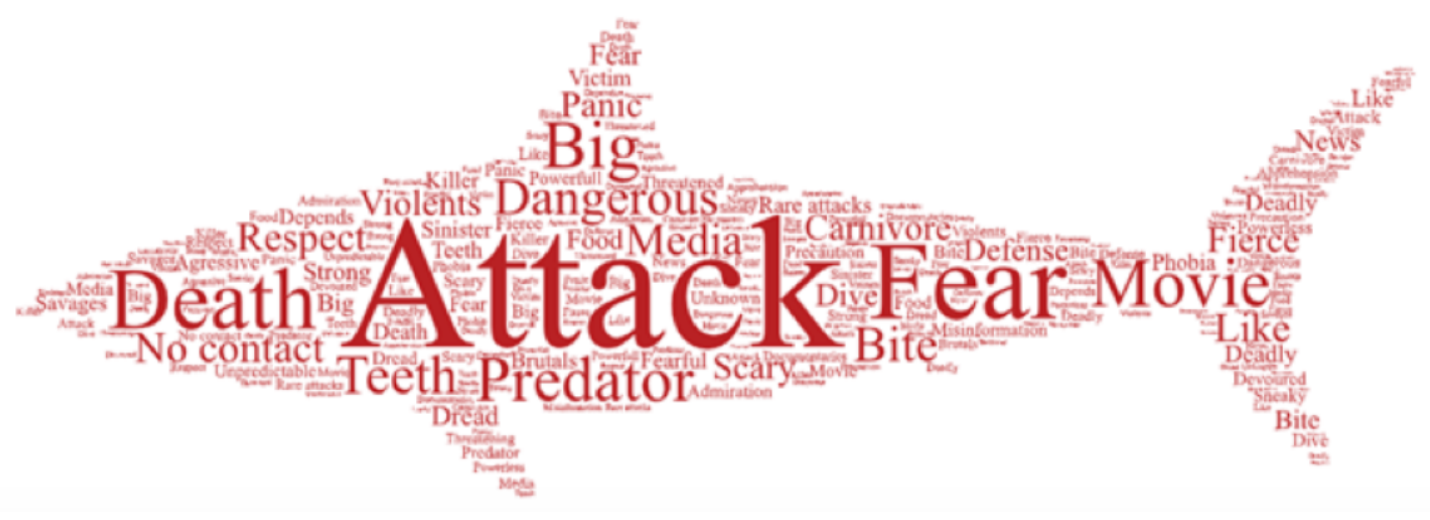

Figure 6. Word Cloud concerning the highest shark scale fear range, between 6-10 (n = 240) of respondents residing in Rio de Janeiro, Brazil, in May 2019.

dents do not represent the entire population, this type of research can assist in engagement, communication and strategy development to promote improvements in general shark perceptions and their conservation.

The demographic profile of study participants was similar to others reported by previous surveys (Liberal et al. 2006; Lucrezi et al. 2018, 2019; Lucrezi and van der Walt 2016; O'Bryhim and Parsons 2015), with the amount of responses given by women much higher than by men. In addition, over half of the responses were from people with higher education levels, indicating that most respondents display high schooling levels. Assessments regarding marine fauna perceptions using high schooled respondents is the most likely to support the conservation of animals such as sharks (Friedrich et al. 2014) and dolphins (Barney et al. 2005) and avoid potential harm to these organisms. In addition, part of the respondents with a college degree consisted of biology students, which have more access to information on shark ecology, resulting in a better formulated opinion on the possible threats to these animals.
Regarding shark information sources, our results corroborate other literature assessments (Liberal et al. 2006; O'Bryhim and Parsons 2015), with documentaries and news indicated as the most efficient means of dissemination. Social networks, however, have emerged as the second most important information medium. This variety of sources produces different knowledge, as different types of media explore animals in particular ways. Documentaries present a more educational character, representing habitat, ecology, behavior and threats, among others, serving as a platform to raise public awareness about the reality of wild animals (O'Bryhim and Parsons 2015). For example, Netflix's "Shark" and Discovery's "Shark Week" documentaries have been previously mentioned as animal knowledge platforms (O'Bryhim and Parsons 2015), providing adequate scientific information rather than sensationalism, contributing to increased public knowledge about sharks, and consequently, concerns regarding their conservation. The literature indicates that media shark fishing coverage can influence public perceptions, providing pos- 


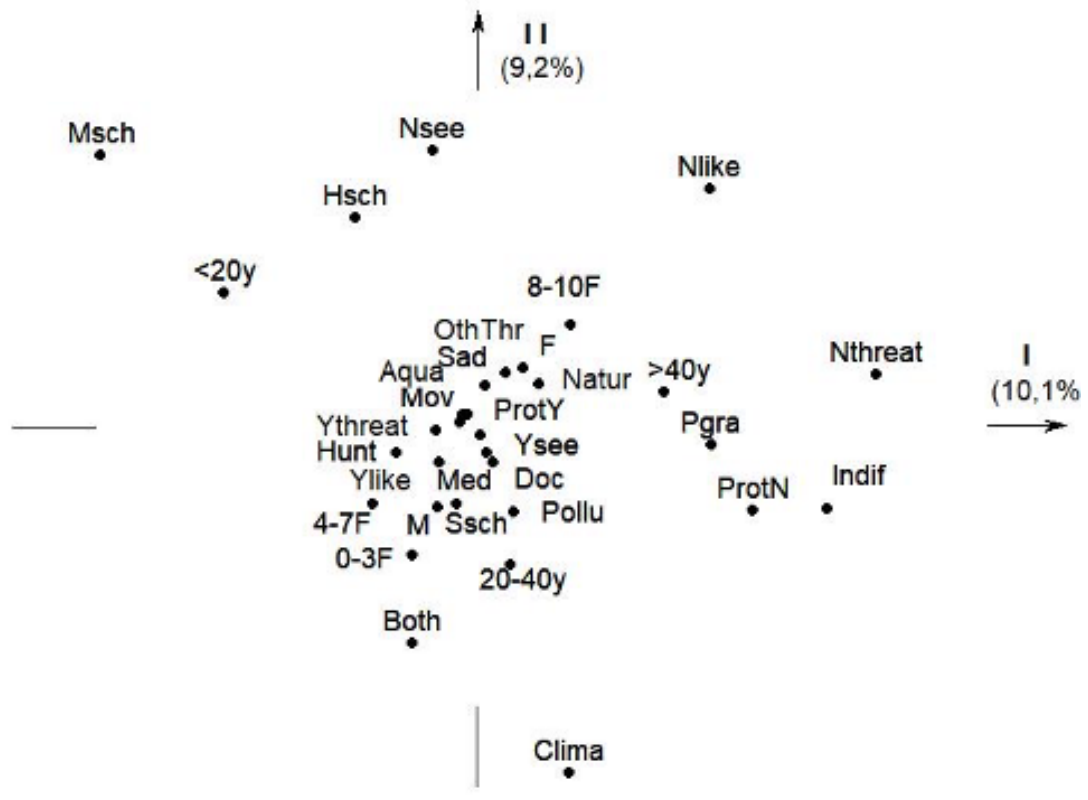

Figure 7. Fatorial analysis of correspondence. Projection of variables on I-II factorial axis. (See code of variables at Table 1).

itive opinions in favor of the conservation of these animals (Friedrich et al. 2014). Similarly, scientific articles consist of information platforms about animals in general, that, due to their specific language, become vehicles that are difficult to read and understand by most of the public, while the other means of information assessed in the current research (news, newspapers/magazines, websites/social networks and movies) tend to present higher negative shark views. Films in which the shark is the protagonist, mostly focus on negative aspects, creating a negative shark image, in contrast to animations, which that among the five most cited media reported herein.

Films tend to focus on negative shark images, using fear of the animal and its intentions as the main basis for its construction, thus developing the culture and popular perception of shark fear (Muter et al. 2013; Neff 2015; Sabatier and Huveneers 2018). This is evidenced by aforementioned films, with "Jaws" as the third most watched. The great white shark (Carcharodon carcharias) image presented in the film still lingers in the public's mind and information outlets remain committed to exploiting the fear this animal embodies whenever a shark incident is reported (Francis 2012).

Most respondents indicated a fear of sharks. This is worrying, since negative attitudes towards sharks are mainly motivated by this emotion (Achen and Bartels 2004). A fear of sharks, coupled with perceptions that shark bites are intentional, leads people to support lethal control policies. However, the "feeling of support for a local population" in relation to sharks contributes to lessen fear and support non-lethal control measures (Pepin-Neff and Wynter 2018). Unfortunately, reducing the fear of sharks in the public is a major challenge, as news, for the most part, contributes to increased fear in humans (Pepin-Neff and Wynter 2019). In addition, fear may also be associated with a frequent lack of contact by most people with these animals (Acuña-Marrero et al. 2018; Friedrich et al. 2014; Neff and Yang 2013).

The results indicate that most respondents have already been in contact with sharks, whether visiting a large aquarium and/or in the wild and demonstrate a desire to repeat the experience. This significantly influences positive shark perceptions. Recent studies have confirmed that people who live in contact with these animals, such as traditional coastal communities, are less afraid and learn to recognize the ecosystem value of these animals (Friedrich et al. 2014; Neff and Yang 2013), and display less negative influence by media information. Direct experience has been recognized as an important component for the development of pro-environmental values (Bogëholz 2006; Miller 2005; Rajecki 1990), such as encounters during recreational dives, that generate positive experiences (Acuña-Marrero et al. 2018). Contrary to what some studies indicate (Lucrezi et al. 2019), visitation aquariums can become teaching and environmental education spaces, promoting animal contact and closeness (Pepin-Neff and Wynter 2018). However, it is not yet known on what scale an aquarium can repli- 
cate natural encounter experiences (Friedrich et al. 2014). Even so, people who frequent these places tend to be more interested in wildlife and display greater knowledge about these animals, contributing to positive conservation attitudes and support (Friedrich et al. 2014; O'Bryhim and Parsons 2015). Thus, a shark sighting in an aquarium is able to empathize people concerning animals, reducing fear and promoting conservation measure sympathy (Pepin-Neff and Wynter 2018).

Despite negative shark perceptions as verified by fear and testimonies, most respondents were not in favor of shark hunting, disapproving of this practice. A similar result was reported in a study conducted in Recife (Pernambuco, northeast of Brazil) (Liberal et al. 2006), where less than $6 \%$ of the respondents suggested this alternative as a solution to reduce incidents with humans. This result is very positive, since members of the "Manifesto 5 - Praia é Nossa" movement came together to capture these animals in order to end incidents with humans in Pernambuco, in 2012. This was also observed in the past, as the film "Jaws" was responsible for increased shark hunting and overfishing, devastating their habitats and negatively impacting shaker populations (Francis 2012). This public feeling of protection against sharks is similar to that reported in recent studies, which emphasize that greater knowledge is indispensable to generate positive attitudes towards sharks, discarding certain practices, such as fishing (Acuña-Marrero et al. 2018; Curtin and Papworth 2018; de la Lama et al. 2018; O'Bryhim and Parsons 2015). In addition, a small percentage of responses was marked "Indifferent". This result does not necessarily indicate that the respondents are not concerned with shark conservation, but the fact that these issues are not commonplace for some people (O'Bryhim and Parsons 2015).

In general, respondents demonstrated relevant knowledge about the threats that sharks suffer, although a small part remained unaware of these issues. This corroborates other literature assessments, in which threat responses focus mainly on overfishing and human action (Friedrich et al. 2014; Shiffman et al. 2020). Most respondents seem to have cited humans as a threat because they do not know exactly how humans pose a threat to sharks. According to Shiffman et al. (2020), the public does not always understand the threats that a certain biological group may suffer, and as a result, support extreme measures to control that threat, which are not always considered adequate by the scientific community (i.e. considering that every threat suffered by sharks comes down to finning and supporting total fisheries eradication).

The shark image in people's minds creates fear (Francis 2012) by exploring the idea that "humans are on the shark menu" (Friedrich et al. 2014) and that they are "man-eaters" with risks of imminent attacks (Neff 2014). However, most respondents demonstrate the notion that the sharks are, instead, the threatened actors in these interactions, not humans, and that changes in the climate, pollution, fishing and extinction, all mentioned by the respondents, comprise threats to sharks. This is, in fact, correct, since about $25 \%$ of all Chondrichthyes are threatened worldwide (Dulvy et al. 2014). Currently, fishing has grown as the main marine threat mechanism (Anderson et al. 2011; McClenachan et al. 2012; Polidoro et al. 2008). Coastal shark species, in particular, suffer from fishing threats and habitat degradation due to anthropogenic action (urban development and pollution, among others), and pelagic species are constantly susceptible to predatory industrial fishing and incidental capture (Dulvy et al. 2014). In addition, "finning" is also an issue, which consists of removing shark fins when the animals are still alive and then discarding them, resulting in a slow and painful death (Dulvy et al. 2017). This practice is dedicated to the fin soup trade, banned in over 40 countries (Davidson et al. 2016; Lack and Sant 2011). However, this cruelty is still exercised worldwide, threatening all shark species, in varying degrees (Clarke et al. 2013; Francis 2012).

The results reported herein demonstrate that shark encounters, in general, comprise positive experiences, and that the small number of negative experiences had no negative impact on respondent attitudes towards the conservation of these animals. These results are similar to other published studies (Lucrezi et al. 2019; O'Bryhim and Parsons 2015). Of the 69 people who had not ever seen a shark or who did not want to see one again, a total of 64 supported their conservation, corroborating the literature (Friedrich et al. 2014).

Despite the negative perception and fear of sharks, only some respondents did not support the conservation of these animals. This is in line with arguments that claim that public opinions are extremely important in supporting conservation (Gibbs and Warren 2014; Lynch et al. 2010; Pepin-Neff and Wynter 2019; Shiffman et al. 2020; Whatmough et al. 2011). Positive knowledge and attitudes towards sharks, most generated from previously acquired knowledge, are the main factors that improve public shark perceptions and support their worldwide conservation ( $\mathrm{Lu}-$ crezi et al. 2019; O'Bryhim and Parsons 2015), and are able to be applied to broader environmental issues (Barney et al. 2005; Fletcher and Potts 2007; Kellert 1985; Kollmuss and Agyeman 2002). The dissemination of quality shark information is a strong enough factor that negative perceptions do not affect shark conservation (O'Bryhim and Parsons 2015), highlighting the importance of conservation actions, likes en- 
vironmental education promoted by different institutions, such as the "AfriOceans Conservation Alliance" (Lucrezi et al. 2019). However, occasional attacks comprise a significant variable that complicates the humans-shark relationship and decreases engagement in conservation issues (Friedrich et al. 2014).

The more varied means of information people have access to, the less fear of sharks the recipients of this knowledge will have, corroborating the literature (Friedrich et al. 2014). However, this analysis did not consider media as categorized into negative and positive, which can influence popular perceptions in different ways. Films like "Sharkwater", the "Fish Fight" (a Channel Four series), the movie "Shark Bait" (which accompanied "Big Fish Fight" a campaign by British NGOs), among others, are positive to sharks from a conservation point of view compared to the traditional negative dramatic media shark representation. This type of coverage may, thus, contribute to increased public interest in the conservation of these animals (Friedrich et al. 2014). As mentioned before, animals have been used in entertainment since the early decades of society, mostly to amaze the public by causing a certain fear, being shown as "dangerous beasts" or "killing machines". With that, the view that was disseminated for the general public was mostly a negative perception of the presented animal and, most of the times, led to bad reactions such as hunting and fishing those animals (Brower, 2005), against their conservation. Nowadays, we still see a sensationalist disclosure of animals, but also a conservative disclosure, that has the objective of sharing important and valid information, is constantly growing between the public, being shared by animal institutions, such as aquariums and zoos, biologists, NGOs and others, assisting animal conservation (Gusset and Dick 2010, Alves and Barboza 2018).

However, these data must be analyzed with caution, as the most positive media reports concerning sharks were observed in animations, which result in significantly higher impacts on younger individuals, as adult people are not so influenced by children's media because they are fanciful and entertaining. Similarly, the respondents usually seek out more shark media, perhaps due to the fact that they present less fear of sharks. The nucleus interviewed in this study is similar to that sampled in another article (Friedrich et al. 2014), in which the interviewees demonstrated affection, knowledge and awareness of the shark situation, which act as barriers and lead to prejudices in negative film representations.

When analyzing respondent answers concerning different means of information, an idea that media vehicles negatively influence people regarding sharks is noted, and some respondents are aware of this. The media, when used as a vehicle for information, but not properly disseminated, can mislead and/or exaggerate information given to the public in understanding environmental problems, stimulating the defense of drastic control measures as the most appropriate (Shiffman et al. 2020). However, other queries are required to better understand the media influence. Thus, future research should include more direct questions such as: "How does the media influence your perception of sharks?", "Do different types of media negatively influence your perception of sharks?" or "What types of media negatively and positively influence your perception of sharks?".

The WordCloud analysis evidenced that milder words related to shark reality, such as respect and lack of information, were used by the public scoring less fear values (scales ranging from 0 to 5 ), such as: "rare attacks", "threatened", "respect", "contactless", "admire" and "disinformation". On the other hand, the public scoring greater fear (6-10) most frequently used words that characterize sharks as predators, such as: "fear", "attack", "predator", "movies", "kill", "bite" and "dangerous". Currently, marine species conservation is considered quite worrying, due to high degradation and habitat loss rates, overfishing and pollution by persistent contaminants. Therefore, assessments concerning factors that contribute to greater shark knowledge are required, as this is key for shark conservation. The present study was relevant in association public perceptions as a result of information sources (films, documentaries, scientific articles and social networks) with the way public opinions evaluate sharks and how this awareness is reflected in conservation support.

The Correspondence factor analysis demonstrated that the variable "<20y" was related to "MSch", "HSch" and "NSee", comprising younger people, with less academic training and who have not yet had contact with sharks. The group of the variable "> 40y" is made up of people with higher education and postgraduate degrees, but with a more negative perception of these animals, considering that they are not threatened and do not need protection and demonstrating indifference to discriminated killing. Some studies show that fear can be more pronounced in older people compared to younger people (Fredrikson et al. 1996), and as the older respondents lived in a time when environmental information was not widely disseminated and the public became more susceptible to films and negative shark media, this fear persists until today. People aged 20-40 are less afraid and in greater contact with current media, such as documentaries and social networks, which corroborate threats to this group, such as overfishing, marine pollution and climate change. The current means of information, compared to older ones, provide the public with more information regarding the conservation status of 
animals and the threats that they suffer, resulting in people in the mentioned age group being less afraid and more informed.

Regarding gender, our analysis indicates that the women interviewed are more afraid of sharks and have no desire to see these animals. This corroborates previous research that generally demonstrate that women are generally more afraid than men, due to several factors, including hormonal status, and tend to avoid situations that can contribute to anxiety and panic (McLean \& Anderson 2009). However, it is important to note that the expressed statements are not definitive conclusions. The $\mathrm{CA}$ is an exploratory technique that highlights trends that appear due to greater or lesser similarity between the response variables.

\section{CONCLUSION}

Considering the results reported herein and the available literature, we conclude that different media types can differentially influence public shark perceptions. These perceptions can be positively influenced by media that present these animals appropriately, like in documentaries, or negatively, with derogatory representations, mainly in films where sharks play the role of villains. Not all representations are consistent with reality and can be distorted to generate certain effects on the public. Popular perception, whether positive or negative, does not seem to affect conservation measure support, which is positive consequence for worldwide shark preservation.

\section{ACKNOWLEDGEMENT}

The authors would like to thank all questionnaire respondents who took some of their time to support this work and shark conservation, permitting this research. This study was supported by the Pontifical Catholic University of Rio de Janeiro (PUC-Rio), Biology and Fishery Technology Laboratory of at the Federal University of Rio de Janeiro (UFRJ) and Instituto Museu Aquário Marinho do Rio de Janeiro (IMAM).

\section{CONFLICT OF INTEREST}

The authors declare no conflicts of interest.

\section{REFERENCES}

Achen C, Bartels L (2004) Blind Retrospection: Electoral Responses to Droughts, Floods, and Shark Attacks. Democracy for Realists 116-145.
Acuña-Marrero D, Cruz-Modino $\mathrm{R}$ de la, Smith ANH, Salinas-de-León P, Pawley MDM, Anderson MJ (2018) Understanding human attitudes towards sharks to promote sustainable coexistence. $\mathrm{Ma}$ rine Policy 91: 122-128.

Alexandre M, Fernandes R (2006) O poder hoje está na mídia. Comum 11: 145-168.

Alves RRN, Souto WMS (2015) Ethnozoology: A Brief Introduction. Ethnobiology and Conservation 4: 1-13.

Alves RRN, Barboza RRD (2018) From Roman Arenas to Movie Screens: Animals in Entertainment and Sport. In: Alves RRN, Albuquerque UP (eds) Ethnozoology: Animals in Our Lives. Academic Press, London, pp. 363-382.

Anderson SC, Flemming JM, Watson R, Lotze HK (2011) Serial exploitation of global sea cucumber fisheries. Fish and Fisheries 12: 317-339.

Andrelo R, Almeida LBC (2015) The media and body image: proposal of media critical reading activities. Comum Mídia Consumo 12: 46-66.

Barbosa-Filho MLV, Ramires M, Mourão JS, Rosa RS, Alves RRN, Costa-Neto EM (2020) Ethnotaxonomy of sharks by expert fishers from South Bahia, Brazil: Implications for fisheries management and conservation. Ethnobiology and Conservation 10: 1-12.

Barney EC, Mintzes JJ, Yen CF (2005) Assessing Knowledge, Attitudes, and Behavior Toward Charismatic Megafauna: The Case of Dolphins. Journal of Environmental Education 36: 41-55.

Berteaux D, Casajus N, Angerbjörn A, Fuglei E (2017) Foreword to Supplement 1: research on a polar species - the Arctic fox. Polar Research 36: 1 .

Bogëholz S (2006) Nature experience and its importance for environmental knowledge, values and action: recent German empirical contributions. Environmental Education Research 12: 65-84.

Bousé D (1998) Are wildlife films really "nature documentaries"? Critical Studies in Media Communication 15: 116-140.

Bousé D (2003) False intimacy: Close-ups and viewer involvement in wildlife films. Visual Studies 18: 123-132.

Brower M (2005) Trophy shots: early North American photographs of nonhuman animals 
and the display of masculine prowess. Society and Animals 13: 13-32.

Brower JE, Zar JH (1984) Field \& laboratory methods for general ecology. W.C. Brown Publishers, Boston.

Buckley KA, Crook DA, Einoder LD, Pillans RD, Smith LDG, Kyne PM (2020) Movement behaviours and survival of largetooth sawfish, Pristis pristis, released from a public aquarium. Aquatic Conservation: Marine Freshwater Ecosystem 1-19.

Clarke SC, Harley SJ, Hoyle SD, Rice JS (2013) Population Trends in Pacific Oceanic Sharks and the Utility of Regulations on Shark Finning. Conservation Biology 27: 197-209.

Cortés E (2000) Life History Patterns and Correlations in Sharks. Reviews in Fisheries Science 8: 299-344.

Cortés E (2002) Incorporating uncertainty into demographic modeling: Application to shark populations and their conservation. Conservation Biology 16: 1048-1062.

Curtin P, Papworth S (2018) Increased information and marketing to specific individuals could shift conservation support to less popular species. Marine Policy 88: 101-107.

Davidson LNK, Krawchuk MA, Dulvy NK (2016) Why have global shark and ray landings declined: Improved management or overfishing? Fish and Fisheries 17: 438-458.

Dulvy NK, Forrest RE (2010) Sharks \& Their Relatives II Chapter 17: Life histories, population dynamics, and extinction risks in Chondrichthyans. CRC Press, London.

Dulvy NK, Fowler SL, Musick JA, Cavanagh RD, Kyne PM, Harrison LR, Carlson JK, Davidson LN, Fordham S V, Francis MP, Pollock CM, Simpfendorfer CA, Burgess GH, Carpenter KE, Compagno LJ, Ebert DA, Gibson C, Heupel MR, Livingstone SR, Sanciangco JC, Stevens JD, Valenti S, White WT (2014) Extinction risk and conservation of the world's sharks and rays. eLife 3: 1-34.

Dulvy NK, Simpfendorfer CA, Davidson LNK, Fordham S V., Bräutigam A, Sant G, Welch DJ (2017) Challenges and Priorities in Shark and Ray Conservation. Current Biology 27: R565-R572.

Fletcher S, Potts J (2007) Ocean citizenship: an emergent geographical concept. Coastal management 35: 511-524.

France R (2019) Ethnobiology and Shifting Base- lines: An Example Reinterpreting the British Isles' Most Detailed Account of a Sea Serpent Sighting as Early Evidence for Pre-Plastic Entanglement of Basking Sharks. Ethnobiology and Conservation 8: 1-31.

Francis B (2012) Before AND After " JAWS": Changing Representations of Shark Attacks. The Australian Association for Maritime History 34: 44-64.

Fredrikson M, Annas P, Fischer H, Wik G (1996) Gender and age differences in the prevalence of specific fears and phobias. Behaviour Research and Therapy 34: 33-39.

Friedrich LA, Jefferson R, Glegg G (2014) Public perceptions of sharks: Gathering support for shark conservation. Marine Policy 47: 1-7.

García VB, Lucifora LO, Myers RA (2008) The importance of habitat and life history to extinction risk in sharks, skates, rays and chimaeras. Proceedings of the Royal Society B: Biological Sciences 275: 83-89.

Gibbs L, Warren A (2014) Killing Sharks: cultures and politics of encounter and the sea. Australian Geographer 45: 101-107.

Gusset M, Dick G (2010) Building a Future for Wildlife? Evaluating the contribution of the world zoo and aquarium community to in situ conservation. International Zoo Yearbook 44: 183191.

Hansen A (2010) Environment, Media and Communication. $2^{\circ}$ edition ed. Routledge, Oxon.

Jefferson RL (2010) Communicating marine environmental health: Connecting science, social and policy values.

Kellert SR (1985) Public perceptions of predators, particularly the wolf and coyote. Biological Conservation 31: 167-189.

Kollmuss A, Agyeman J (2002) Mind the Gap: why do people act environmentally and what are barriers to pro-environmental behavior? Environmental Education Research 8: 239-260.

de la Lama RL, de la Puente S, Riveros JC (2018) Attitudes and misconceptions towards sharks and shark meat consumption along the Peruvian coast. PLOS ONE 13: 1-16.

Lack M, Sant G (2011) The future of sharks: a review of action and inaction. Traffic International.

Liberal CN, Santos GKN, Demétrio K de M, Morimura MM, Vasconcelos SD (2006) Shark at- 
tacks in Pernambuco, Brazil: analysis of bather's perceptions and environmental factors. Tropical Oceanography 34: 86-99.

Lucrezi S, Ellis S, Gennari E (2019) A test of causative and moderator effects in human perceptions of sharks, their control and framing. Marine Policy 109: 103687.

Lucrezi S, Geldenhuys L-L, Van der Merwe P, Saayman M (2018) Utility of Users Data and Their Support for Differential Beach Management in South Africa. South Africa, pp. 933-960.

Lucrezi S, van der Walt MF (2016) Beachgoers' perceptions of sandy beach conditions: demographic and attitudinal influences, and the implications for beach ecosystem management. Journal of Coastal Conservation 20: 81-96.

Lynch AMJ, Sutton SG, Simpfendorfer CA (2010) Implications of recreational fishing for elasmobranch conservation in the Great Barrier Reef Marine Park. Aquatic Conservation: Marine and Freshwater Ecosystems 20: 312-318.

Marques RA, Guimarães Julio T, Sole-Cava AM, Vianna M (2020) A new strategy proposal to monitor ray fins landings in south-east Brazil. Aquatic Conservation: Marine Freshwater Ecosystem 30: $68-85$.

McClenachan L, Cooper AB, Carpenter KE, Dulvy NK (2012) Extinction risk and bottlenecks in the conservation of charismatic marine species. Conservation Letters 5: 73-80.

Miller JR (2005) Biodiversity, conservation and the extinction of experience. Trends in Ecology and Evolution 20: 430-434.

Musick JA (1999) Life in the Slow Lana: Ecology and conservation of long-lived marine animals. American Fisheries Society, Maryland.

Muter BA, Gore ML, Gledhill KS, Lamont C, Huveneers C (2013) Australian and U.S. News Media Portrayal of Sharks and Their Conservation. Conservation Biology 27: 187-196.

Neff C (2014) Human perceptions and attitudes towards sharks: Examining the predator policy paradox. Sharks: Conservation, Governance and Management. Routledge, pp. 127-152.

Neff C (2015) The Jaws Effect: How movie narratives are used to influence policy responses to shark bites in Western Australia. Australian Journal of Political Science 50: 114-127.

Neff CL, Yang JYH (2013) Shark bites and pub- lic attitudes: Policy implications from the first before and after shark bite survey. Marine Policy 38: 545-547.

O'Bryhim JR, Parsons ECM (2015) Increased knowledge about sharks increases public concern about their conservation. Marine Policy 56: $43-47$.

Pepin-Neff C, Wynter T (2019) Save the sharks: reevaluating and (re)valuing feared predators. Human Dimensions of Wildlife 24: 87-94.

Pepin-Neff CL, Wynter T (2018) Reducing fear to influence policy preferences: An experiment with sharks and beach safety policy options. Marine Policy 88: 222-229.

Polidoro BA, Livingstone SR, Carpenter KE, Hutchinson B, Mast RB, Pilcher NJ, Mitcheson YS de, Valenti S V. (2008) Status of the world's marine species." Wildlife in a Changing World-An Analysis of the 2008 IUCN Red List of Threatened Species. pp. 55-65.

Rajecki DW (1990) Attitudes, themes and advances. $2^{\circ}$ edition ed. Sinauer Associates, Inc, Sunderland.

Sabatier E, Huveneers C (2018) Changes in media portrayal of human-wildlife conflict during successive fatal shark bites. Conservation and Society 16: $338-350$.

Saldaña-Ruiz LE, Sosa-Nishizaki O, Cartamil D (2017) Historical reconstruction of Gulf of California shark fishery landings and species composition, 1939-2014, in a data-poor fishery context. Fisheries Research 195: 116-129.

Shiffman DS, Bittick SJ, Cashion MS, Colla SR, Coristine LE, Derrick DH, Gow EA, Macdonald CC, O'Ferrall MM, Orobko M, Pollom RA, Provencher J, Dulvy NK (2020) Inaccurate and Biased Global Media Coverage Underlies Public Misunderstanding of Shark Conservation Threats and Solutions. Iscience 23(6): 101205.

Whatmough S, Van Putten I, Chin A (2011) From hunters to nature observers: A record of $\mathbf{5 3}$ years of diver attitudes towards sharks and rays and marine protected areas. Marine and Freshwater Research 62: 755-763.

Received: 15 July 2020 Accepted: 25 November 2020 Available: 10 December 2020 